\title{
Case of Gastric Diffuse Large B-Cell Lymphoma
}

\author{
Usman A. Pirzada ${ }^{a}$ Kishore Kumar ${ }^{b}$ Hassan Tariq ${ }^{b}$ Masooma Niazi ${ }^{c}$ \\ Jasbir Makker ${ }^{b}$ \\ aDepartment of Medicine, Bronx Lebanon Hospital Center, Bronx, NY, USA; ${ }^{b}$ Division of \\ Gastroenterology, Bronx Lebanon Hospital Center, Bronx, NY, USA; 'Department of \\ Pathology, Bronx Lebanon Hospital Center, Bronx, NY, USA
}

\section{Keywords}

Gastric cancer · Gastric carcinoma · Lymphoma

\begin{abstract}
The gastrointestinal $(\mathrm{Gl})$ tract is the predominant site of extra nodal lymphoma involvement. In the United States (US), gastric lymphoma is the most common extra nodal site of lymphoma. Most of these lesions are either extra nodal marginal zone $B$ cell lymphoma of mucosa associated lymphoid tissue (MALT) type or diffuse large $B$ cell lymphoma (DLBCL). We report a case of diffuse large B-Cell Gastric Lymphoma who initially presented with sore throat, dysphagia and hiccups for a few months. Esophagogastroduodenoscopy showed lower esophageal stenosis and a large, infiltrative, ulcerated, circumferential mass at the gastro esophageal junction and cardia. Histopathology showed diffuse large B cell lymphoma. Positron emission tomography scan showed advanced disease with presence of lymph nodes on both sides of the diaphragm. The patient was considered to have Stage IV gastric lymphoma. Subsequently, he was treated with R-CHOP regimen (rituximab, cyclophosphamide, hydroxydaunorubicin, oncovin (vincristine), and prednisone).

(C) 2019 The Author(s)

Published by S. Karger AG, Basel
\end{abstract}




\section{Case Reports in Oncology}

\section{Introduction}

The gastrointestinal (GI) tract is the predominant site of extra nodal lymphoma involvement. In the United States (US), gastric lymphoma is the most common extra nodal site of lymphoma. Most of these lesions are either extra nodal marginal zone B cell lymphoma of mucosa associated lymphoid tissue (MALT) type or diffuse large B cell lymphoma (DLBCL). We report a case of diffuse large B-Cell Gastric Lymphoma.

\section{Case Presentation}

A 63-year-old man presented to the Emergency Department (ED) with complaints of sore throat for the past 5 days. He also reported symptoms of dysphagia to solids only and intermittent hiccups during meals for two months. He denied any history of abdominal pain, constipation, diarrhea, weight loss, nausea, vomiting, fever or night sweats. He had no significant prior medical or surgical history and also denied taking any medications. He did not smoke cigarettes, drink alcohol, or use illicit drugs. Family history is insignificant for any malignancy. On examination, his vital signs were normal and systemic examination was unremarkable. He underwent a computed tomography (CT) Neck Soft Tissue without contrast which did not show any acute findings. He recently underwent screening colonoscopy, which was significant for low grade tubular adenoma. He was scheduled for an esophagogastroduodenoscopy (EGD) which showed lower esophageal stenosis at the distal esophagus, which could not be traversed with a regular scope. Ultrathin upper endoscope was used to pass the stenosed esophageal area and further examination showed a large, infiltrative, ulcerated, circumferential mass at the gastro esophageal junction and cardia (see Fig. 1 and 2). Subsequent biopsy revealed diffuse large B cell lymphoma (DLBCL) of the gastro esophageal junction and cardia (Fig. 3 and 4). On immunohistochemical stain, the tumor cells were positive for leukocyte common antigen (LCA), CD20 (CD; cluster of differentiation), CD79 and were negative for cytokeratin AE1/AE3, CD3, CD5, CD10, CD43, CYCLIN-D1, B- cell lymphoma 2 antibodies and B cell lymphoma 6 antibodies (see Fig. 5 and 6). The Ki 67 index was reportedly very high.

Further workup for tumor staging was performed. Computed tomography (CT) of the abdomen and Pelvis with contrast, showed a mass like thickening of the distal esophagus and proximal stomach with probable nodal involvement. PET Scan showed abnormal activity in distal esophagus, gastric fundus and nodes above and below the diaphragm. Table 1 shows laboratory parameters. The diagnosis of Stage IV (esophagus and gastric involvement) DLBCL was made and the patient was started on R-CHOP chemotherapy regimen (RCHOP; rituximab, cyclophosphamide, hydroxydaunorubicin, oncovin (vincristine), and prednisone). Table 1 showed laboratory parameters.

\section{Discussion}

DLBCL is the most common histologic subtype of non-Hodgkin lymphoma (NHL). It accounts for approximately $25 \%$ of non-Hodgkin's lymphoma (NHL) cases in the developed world [1]. In the United States, the incidence of DLBCL is approximately 7 cases per 100,000 


\section{Case Reports in Oncology}

persons per year $[1,2]$. Like most other NHLs, there is a male predominance with approximately 55 percent of cases occurring in men [1]. The incidence increases with age with the mean age at presentation being 64 years, but appears to be younger for Blacks than for Caucasian Americans [3]. Diffuse large B-cell lymphoma (DLBCL) is an aggressive NHL in which survival without treatment is measured in months. Sixty percent of patients will present with advanced stage DLBCL (usually stage III or IV disease) while 40 percent have a more localized disease $[5,6]$. Patients with DLBCL typically present with symptoms of a rapidly enlarging mass often with associated lymphadenopathy. Extra nodal involvement is common among those presenting with stage I/II disease [4]. Systemic "B" symptoms (fever, weight loss, night sweats) are observed in about 30 percent of patients, and the serum lactate dehydrogenase $(\mathrm{LDH})$ is elevated in over one-half of them $[5,6]$. The diagnosis of DLBCL is best made based by excisional tissue biopsy. Staining for pan-B cell markers, such as CD20 and CD79a, is enough to establish the diagnosis in many cases, but a much broader set of stains may be needed in cases with atypical morphological features.

The initial treatment of DLBCL is dependent on the extent of disease. Patients with DLBCL are generally classified as having either limited stage disease (usually stage I or II) or advanced stage disease (usually stage III or IV) based on whether the tumor can be contained within one irradiation field. For patients with limited stage gastric DLBCL, treatment regimen comprises either six cycles of R-CHOP alone or three cycles of R-CHOP followed by involved-field radiation therapy (IFRT). Patients with advanced disease need to be treated more aggressively [79]. Surgery is reserved for patients with complications such as perforation, obstruction, or intractable bleeding, for both limited stage and advanced disease. Positron emission tomography (PET) scan should be obtained 6-8 weeks after chemo immunotherapy and 12 weeks after the completion of radiotherapy. Response to treatment is determined using information gathered from the post-treatment history, physical, and PET/CT scan results. Following the completion of therapy, restaging and documentation of complete remission should be done. The patient should be seen at periodic intervals to monitor for treatment complications and assess for possible relapse of the disease. Our patient is still receiving R-CHOP chemotherapy regimen. His clinical course is complicated by mild myelosuppression as a side effect of chemotherapy without any adverse event.

\section{Conclusion}

DLBCL is a common gastrointestinal tract lymphoma usually affecting elderly males. It usually presents at advanced stage. Treatment mainly comprises chemotherapy. Here we present a case of gastric DLBCL with an intent to make physicians aware of this common lymphoma which is aggressive and fatal if left untreated.

\section{Statement of Ethics}

Consent for publication was obtained. 


\section{Funding Sources}

This manuscript was not funded.

\section{Disclosure Statement}

The authors have no conflict of interest.

\section{Author Contributions}

All authors have contributed in writing and reviewing the manuscript.

\section{References}

1 Morton LM, Wang SS, Devesa SS, Hartge P, Weisenburger DD, Linet MS. Lymphoma incidence patterns by WHO subtype in the United States, 1992-2001. Blood. 2006 Jan;107(1):265-76.

2 Smith A, Howell D, Patmore R, Jack A, Roman E. Incidence of haematological malignancy by sub-type: a report from the Haematological Malignancy Research Network. Br J Cancer. 2011 Nov;105(11):1684-92.

3 Shenoy PJ, Malik N, Nooka A, Sinha R, Ward KC, Brawley OW, et al. Racial differences in the presentation and outcomes of diffuse large B-cell lymphoma in the United States. Cancer. 2011 Jun;117(11):2530-40.

4 Hui D, Proctor B, Donaldson J, Shenkier T, Hoskins P, Klasa R, et al. Prognostic implications of extranodal involvement in patients with diffuse large B-cell lymphoma treated with rituximab and cyclophosphamide, doxorubicin, vincristine, and prednisone. Leuk Lymphoma. 2010 Sep;51(9):1658-67.

5 Armitage JO, Weisenburger DD. New approach to classifying non-Hodgkin's lymphomas: clinical features of the major histologic subtypes. Non-Hodgkin's Lymphoma Classification Project. J Clin Oncol. 1998 Aug;16(8):2780-95.

6 A clinical evaluation of the International Lymphoma Study Group classification of non-Hodgkin's lymphoma. The Non-Hodgkin's Lymphoma Classification Project. Blood. 1997 Jun;89(11):3909-18.

7 Pfreundschuh M, Trümper L, Osterborg A, Pettengell R, Trneny M, Imrie K, et al.; MabThera International Trial Group. CHOP-like chemotherapy plus rituximab versus CHOP-like chemotherapy alone in young patients with good-prognosis diffuse large-B-cell lymphoma: a randomised controlled trial by the MabThera International Trial (MInT) Group. Lancet Oncol. 2006 May;7(5):379-91.

8 Lamy T, Damaj G, Soubeyran P, Gyan E, Cartron G, Bouabdallah K, et al.; LYSA Group. R-CHOP 14 with or without radiotherapy in nonbulky limited-stage diffuse large B-cell lymphoma. Blood. 2018 Jan;131(2):17481.

9 Miller TP, Dahlberg S, Cassady JR, Adelstein DJ, Spier CM, Grogan TM, et al. Chemotherapy alone compared with chemotherapy plus radiotherapy for localized intermediate- and high-grade non-Hodgkin's lymphoma. N Engl J Med. 1998 Jul;339(1):21-6. 


\section{Case Reports in Oncology}

www.karger.com/cro

Pirzada et al.: Case of Gastric Diffuse Large B-Cell Lymphoma

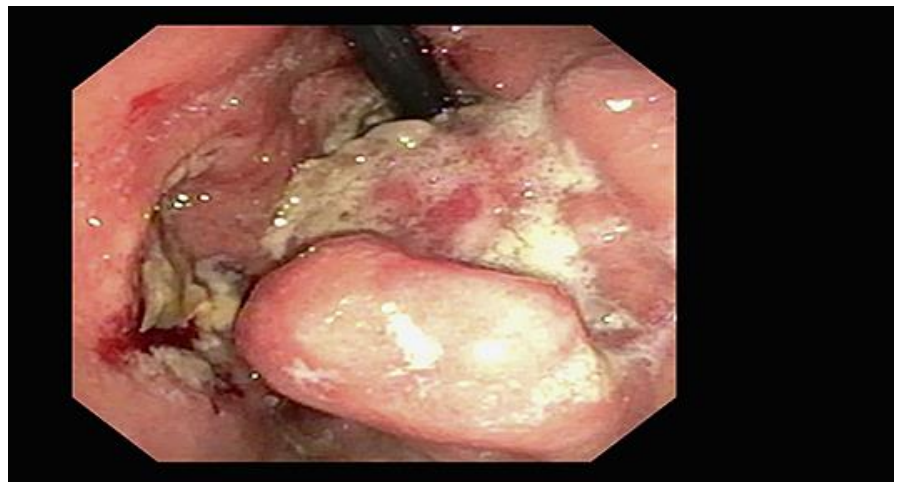

Fig. 1. Esophagogastroduodenoscopy showing infiltrative mass at GE Junction and cardia on retroflexion.

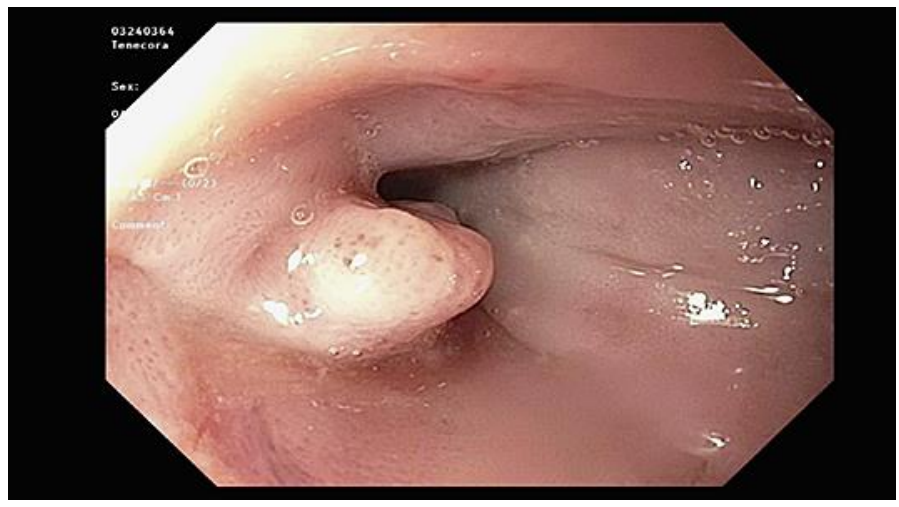

Fig. 2. Esophagogastroduodenoscopy showing distal esophageal mass with luminal narrowing causing stenosis. 


\section{Case Reports in Oncology}

Case Rep Oncol 2019;12:39-46

DOI: $10.1159 / 000496332$

(C) 2019 The Author(s). Published by S. Karger AG, Basel www.karger.com/cro

Pirzada et al.: Case of Gastric Diffuse Large B-Cell Lymphoma

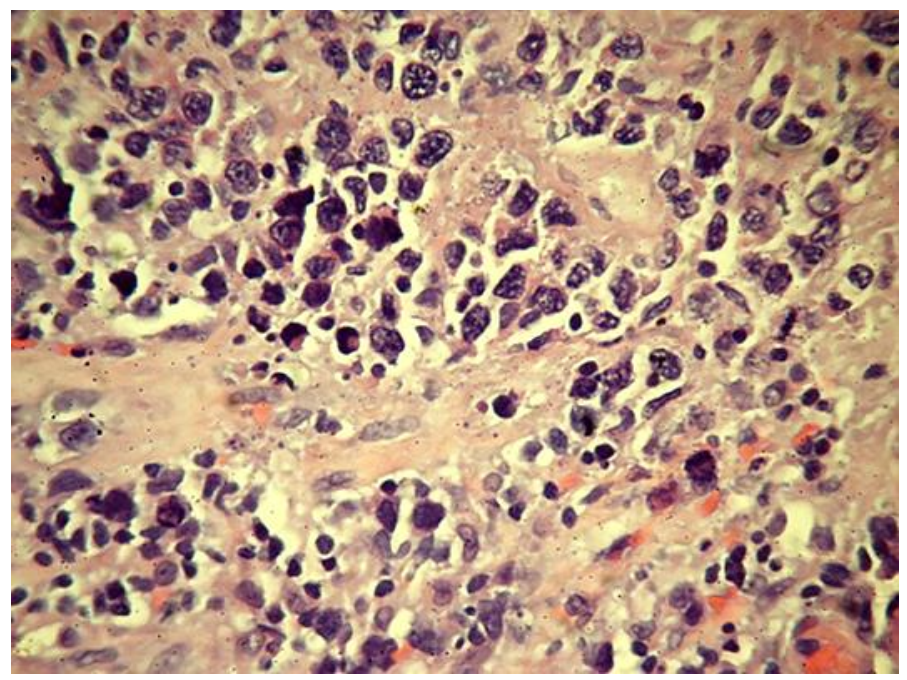

Fig. 3. Hematoxylin and eosin stain - showing Large atypical lymphocytes (Magnification 400x).

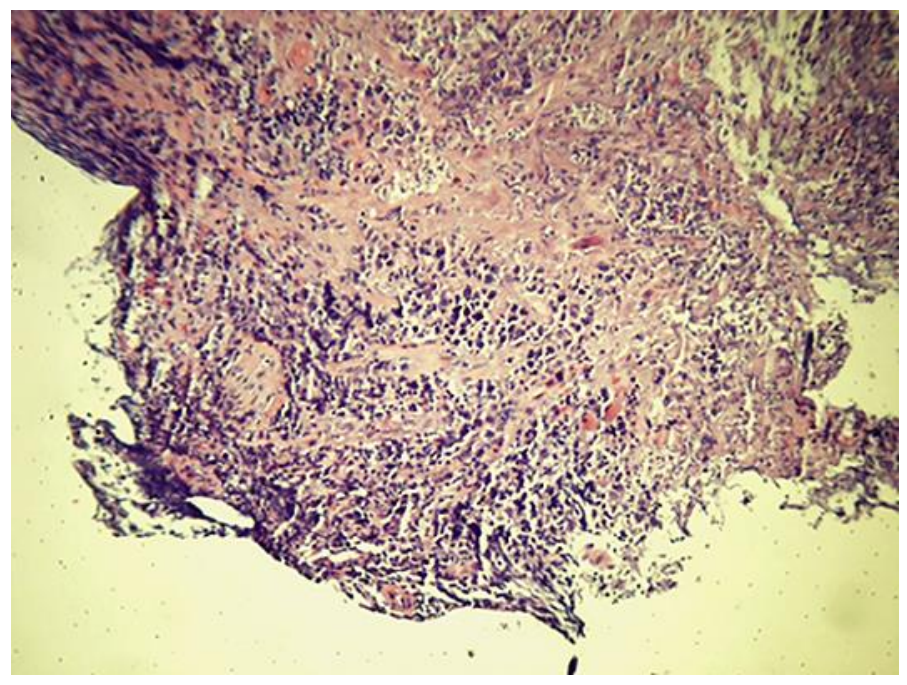

Fig. 4. Large atypical lymphocytes with tumor necrosis (Hematoxylin and eosin stain - Magnification $100 \times)$. 


\section{Case Reports in Oncology}

Case Rep Oncol 2019;12:39-46

DOI: $10.1159 / 000496332$

(C) 2019 The Author(s). Published by S. Karger AG, Basel

Pirzada et al.: Case of Gastric Diffuse Large B-Cell Lymphoma

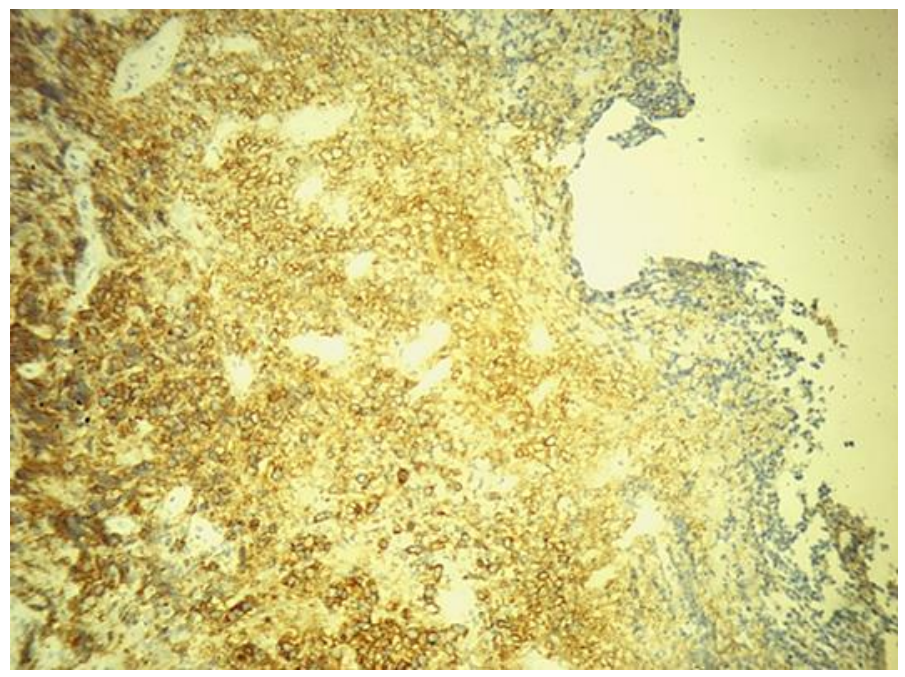

Fig. 5. Gastric B cell Lymphoma. CD20+- Immunohistochemical stain - B cell marker.

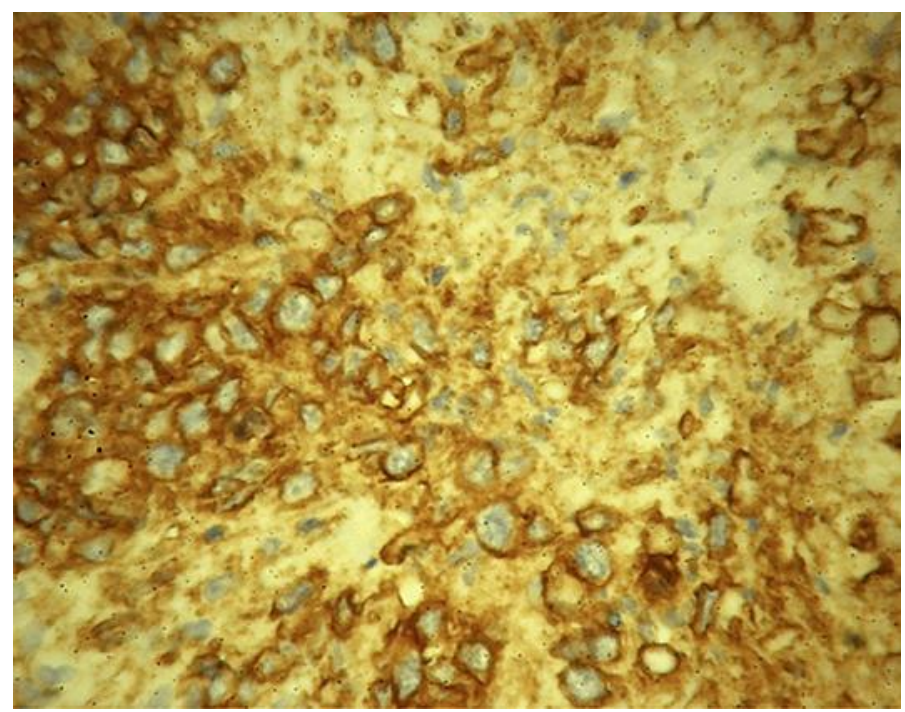

Fig. 6. Gastric B cell Lymphoma. CD20+ - Immunohistochemical stain - B cell marker (Magnification 400×). 


\section{Case Reports in Oncology}

Case Rep Oncol 2019;12:39-46

DOI: $10.1159 / 000496332$ (c) 2019 The Author(s). Published by S. Karger AG, Basel
www.karger.com/cro

Pirzada et al.: Case of Gastric Diffuse Large B-Cell Lymphoma

Table 1. Laboratory parameters

\begin{tabular}{lll}
\hline & Values & Normal range \\
\hline White blood cell (WBC) count & $4,500 / \mu \mathrm{L}$ & $4,800-10,800 / \mu \mathrm{L}$ \\
Hemoglobin (Hb) & $13.2 \mathrm{~g} / \mathrm{dL}$ & $12-16 \mathrm{~g} / \mathrm{dL}$ \\
Mean corpuscular volume(MCV) & $86.7 \mathrm{FL}$ & $80-96 \mathrm{FL}$ \\
Platelet (Plt) count & $197,000 / \mu \mathrm{L}$ & $150,000-400,000 / \mu \mathrm{L}$ \\
Partial thromboplastin time (PTT) & $27.8 \mathrm{~s}$ & $26.1-33.8 \mathrm{~s}$ \\
International normalized ratio(INR) & 1 & $0.8-1.2$ \\
Hepatitis B surface antigen & Negative & Negative \\
Hepatitis C virus antibody (HCV-Ab) & Negative & Negative \\
HIV Antibody & Negative & Negative \\
Serum LDH & $284 \mathrm{unit} / \mathrm{L}$ & $110-210 \mathrm{unit} / \mathrm{L}$ \\
Serum uric acid & $3.1 \mathrm{mg} / \mathrm{dL}$ & $2.5-8.0 \mathrm{mg} / \mathrm{dL}$ \\
Liver function test & WNL & \\
Renal Function Tests & WNL & \\
\end{tabular}

WNL, within normal limit. 